\title{
Histological and immunohistochemical study of the role of stem cells, conditioned medium and microvesicles in treatment of experimentally induced acute kidney injury in rats
}

\author{
Original \\ Article \\ Maysara Salem ${ }^{1}$ Omayma Helal ${ }^{1}$ Hala Metwaly', Asmaa El Hady ${ }^{1}$ and \\ Shaimaa Ahmed ${ }^{1}$ \\ ${ }^{1}$ Histology and Cell Biology Department, Faculty of Medicine, Benha University, Banha, Egypt \\ ${ }^{2}$ Clinical Pathology Department, Faculty of Medicine, Cairo University, Cairo, Egypt
}

\begin{abstract}
Background: Acute kidney injury (AKI) is a major health problem associated with high morbidity and mortality rates. Mesenchymal stem cells (MSCs) have revealed advantages for therapeutic use in medical practice. Microvesicles (MVs) are membranous, cell-derived vesicles released by MSCs into their microenvironment. The conditioned medium (CM) is the medium surrounding MSCs.

Aim of the Work: This study aimed to investigate the therapeutic potential of MSCs, their CM and microvesicles (MVs) on experimentally induced acute kidney injury in rats.

Materials and Methods: Fifty-five rats were divided into five groups:

Group I (control group). Group II: given glycerol intramuscularly. Group III: given glycerol then MSCs. Group IV: given glycerol then CM. Group V: given glycerol then MVs. Kidney specimens were processed for H\&E and Ki-67 staining and EM studies.

Results: Subgroup IIA revealed vacuolation of the cytoplasm, flattening of the epithelial lining the tubules, extrusion of cytoplasm and nuclei into luminal spaces, deeply stained nuclei, and hyaline material in tubular lumina. EM examination of proximal and distal convoluted tubules showed multiple vacuoles, lysosomes, loss of continuity of apical cell membrane, presence of debris in the lumina and vacuolated mitochondria. Group IIB revealed poor improvement with persistence of most lesions. Groups III, VI and V showed amelioration of most of these lesions, and decrease in blood urea and serum creatinine levels.

Conclusion: Mesenchymal stem cells, CM and MVs ameliorate induced AKI and with little differences in their effectiveness. CM and MVs can be used in treating diseases.
\end{abstract}

Key Words: Acute kidney injury, conditioned medium, glycerol, Ki-67, mesenchymal stem cells, microvesicles

Revised: 16 May 2017, Accepted: 6 June 2017

Corresponding Author: Maysara Salem, Tel.: 0403301435, E-mail: maysara.m.salem@gmail.com

ISSN: 2536-9172, June 2017, Vol. 1, No. 1

\section{INTRODUCTION}

Acute kidney injury (AKI) is a complex pathophysiological response with involvement of oxidative stress accumulation, inflammatory response, tubular cell damage and endothelial microvasculature dysfunction, all of which have deleterious effects on the tubular cells ${ }^{[1]}$.

The most commonly used model for studying acute renal failure is the intramuscular injection of glycerol into the experimental animals, which induces rhabdomyolysis. Rhabdomyolysis-induced AKI develops following skeletal muscle trauma releasing toxic doses of myoglobin and other intracellular proteins into the circulation ${ }^{[2]}$.

The mesenchymal stem cells (MSCs) are adult mesodermal undifferentiated stem cells having the capability to differentiate into cell lineages of connective tissue or other cells ${ }^{[3]}$. Several studies have showed that stem cells enhance repair of tissue by secretion of factors that increase proliferation and stimulate differentiation of endogenous stem-like progenitors present in varies tissues, enhance regeneration of injured cells and decrease inflammatory and immune reactions ${ }^{[4]}$.

Mesenchymal stem cells have showed many advantages for therapeutic usage such as strong immunosuppressive effects, capability to migrate to the tissue injury sites, lack of ethical issues and better safety of allogeneic MSCs after infusion. However, several problems can occur such as the unwanted differentiation of mesenchymal lineages, high risk of cancer transformation of MSCs and their targeted differentiation may be suboptimal[ ${ }^{[5]}$. 
The conditioned medium (CM) is prepared by culturing the MSCs without fetal serum followed by filtration to remove the cells. This medium contains soluble factors secreted by the MSCs. Also, it contains what is called exosomes- like microvesicles derived from the MSCs. The CM may be used instead of MSCs in treating acute kidney injury, thus avoiding cell transplantations ${ }^{[5,6]}$.

Microvesicles (MVs) are nano-sized lipid membranous vesicles approximately $40-1000 \mathrm{~nm}$ in diameter released by all cells both in vivo and in vitro. They are released physiologically under normal conditions but their rate of release is higher under pathological conditions such as degeneration and tumors. Once released they end up in the systemic circulation and have been found and characterized in all body fluids such as serum, plasma, cerebrospinal fluid, breast milk, ascetic fluid and urine.

MVs are composed of membrane fragments enclosing ribonucleic acids, bioactive lipids and cytoplasmic proteins. In general, the content of MVs, reflects that of the cells of their origin ${ }^{[7]}$.

\section{AIM OF THE WORK}

The present study aimed to investigate the therapeutic potential of bone-marrow (BM) derived MSCs, their CM and MSCs derived microvesicles (MVs) on experimentally induced acute kidney injury in rats by glycerol.

\section{MATERIALS AND METHODS}

The present study was performed on 55 adult male albino rats, with an average weight of $180-200$ grams. Strict care and cleaning measures were utilized to keep the animal in a normal healthy state; the animals were kept in animal cages under the prevailing atmospheric conditions. They were kept on normal balanced diet and tap water. All ethical protocols for animal treatment were followed. All animal experiments received approval from Institutional Animal Care Committee. Animal care was provided by Animal House Unit of Kasr Al-Ainy, Faculty of Medicine, Cairo University.

\section{Drugs:}

A- Glycerol was obtained from Sigma company (Cairo, Egypt) and given intramuscularly in a dose of $8 \mathrm{ml}$ of $50 \%$ solution of glycerol $/ \mathrm{kg}$ body weight diluted in normal saline according to Kim et al. ${ }^{[8]}$.

B- BM-derived MSCs were prepared in the Clinical Pathology Department, Kasr Al-Ainy Faculty of Medicine, and were used at a dose of 2 million stem cells in $0.5 \mathrm{ml}$ of phosphate buffered solution (PBS) and were injected intravenously (i.v.) in caudal vein of each rat in group III. They were prepared according to some investigators ${ }^{[9]}$.
C- Conditioned medium was prepared from MSCs cultured for 24 hours with Dulbecco's modified Eagle's medium (DMEM) without fetal bovine serum (FBS). After this period, the medium was collected, centrifuged at 1000 round per minute (rpm) for 5 minutes then at $2500 \mathrm{rpm}$ for 15 minutes and filtered through $0.45 \mu \mathrm{m}$ filter to remove the cells. Each animal received $0.5 \mathrm{ml}$ of $\mathrm{CM}$ delivered intravenously in caudal vein ${ }^{[5,6]}$.

D- Microvesicles were prepared from the conditioned medium by ultracentrifugation by thermo scientific ultracentrifuge in Biochemistry Department, Kasr Al-Ainy Faculty of Medicine. The medium was ultracentrifuged at $100,000 \mathrm{~g}$ for one hour at $4^{\circ} \mathrm{C}$ to pellet of MVs. The pellets were taken and suspended in PBS. This suspension was submitted to a second ultracentrifugation in the same conditions to pellet $\mathrm{MVS}^{[10]}$. The protein content of MVs was quantified by Bradford method. The MV quantification was analyzed by protein concentration and each animal received $15 \mu \mathrm{g}$ of MVs dissolved in $0.5 \mathrm{ml}$ of (PBS) delivered intravenously ${ }^{[11]}$

\section{Animals:}

Animals were divided into 5 groups as follows:

Group I (control group): It included 30 rats and were divided into four subgroups.

Subgroup IA: Ten rats were kept without any intervention, 5 rats were sacrificed at the third day and the other 5 rats were sacrificed at the tenth day after the onset of the experiment.

Subgroup IB: Ten rats were given $8 \mathrm{ml} / \mathrm{kg}$ body weight saline by intramuscular injection distributed equally in both hind limbs, five rats were sacrificed 3 days after the onset of the experiment and the other 5 rats were sacrificed 10 days after the onset of the experiment.

Subgroup IC: Five rats were given $0.5 \mathrm{ml}$ of PBS by intravenous injection in caudal vein and were sacrificed 10 days after the onset of the experiment.

Subgroup ID: Five rats were given $0.5 \mathrm{ml}$ of DMEM media (I.V.) in caudal vein and were sacrificed 10 days after the onset of the experiment. Group II (affected group): It included 10 rats. Rats were given single injection of glycerol intramuscularly at a dose of $8 \mathrm{ml}$ of $50 \%$ solution of glycerol $/ \mathrm{kg}$ body weight distributed equally in both hind limbs. The animals were divided into 2 subgroups (5 rats each):

Subgroup IIA: the animals were sacrificed 3 days after glycerol injection.

Subgroup IIB: the animals were sacrificed 10 days after glycerol injection. 
Group III (stem cell group): It included 5 rats. Rats were given a single dose of about 2 million MSCs in 0.5 $\mathrm{ml}$ PBS in caudal vein 3 days after glycerol administration. They were sacrificed at 10th day after glycerol injection.

Group IV (conditioned medium group): It included 5 rats, each rat was given a single dose of $0.5 \mathrm{ml}$ of $\mathrm{CM}$ in caudal vein 3 days after glycerol injection. They were sacrificed 10 days after glycerol injection.

Group V (microvesicles group): It included 5 rats, each rat was given MVs at a dose of $15 \mu \mathrm{g}$ dissolved in $0.5 \mathrm{ml}$ of PBS in caudal vein 3 days after being given glycerol. They were sacrificed 10 days after glycerol injection.

The fasted rats were anesthetized with ether and sacrificed by cervical dislocation; thereafter, animals were dissected and specimens from the right kidneys were taken from the rats of all groups.

The kidney specimens were fixed in $10 \%$ buffered formal saline, processed to obtain paraffin sections of $5 \mu \mathrm{m}$ thickness, and mounted on glass slides for haematoxylin and eosin (H\&E) staining and Prussian blue stain. Other sections were mounted on positively charged slides for immunohistochemical analysis for Ki-67 staining marker for cell proliferation and regeneration ${ }^{[12]}$.

\section{Electron microscopic study}

Specimens from the right kidneys were fixed in $2.5 \%$ glutaraldehyde and postfixed in 1\% osmium tetroxide. The specimens were processed according Suvarna et al. ${ }^{[12]}$ in the Histology and Cell Biology Department, Faculty of Medicine, Cairo University. Semi-thin sections $(0.51-\mu \mathrm{m})$ were prepared and stained with toluidine blue for proper orientation. Ultrathin sections $(50-80 \mathrm{~nm})$ were prepared from selected areas of the semi-thin sections, mounted on copper grids, stained with uranyl acetate and lead citrate, and examined by using JEOL transmission electron microscope (JEM-100 SX; JEOL Tokyo, Japan) in the Electron Micro $\neg$ scope Unit, Faculty of Medicine, Tanta University, Tanta, Egypt.

\section{Immunohistochemical study}

An immunohistochemical reaction was carried out using the labelled streptavidin-biotin system. The antiki-67 primary antibody was a rabbit polyclonal antibody (Catalogue Number RB-9043-R7, Lab Vision Neomarker; Lab Vision, Fremont, California, USA). The universal kit used was biotinylated secondary antibody. The slides were counterstained with Mayer's haematoxylin before mounting. Positive results for the Ki-67 immune reaction were indicated by brown staining of the nucleus. As a negative control, the primary antibody was replaced by $\mathrm{PBS}^{[12]}$.

\section{Labelling of MSCs}

MSCs were marked using $50 \mu \mathrm{m}$ iron oxide in $4 \mathrm{ml}$ RPMI media for $30 \mathrm{~min}$, followed by centrifugation at $2000 \mathrm{rpm}$ for $10 \mathrm{~min}$, to separate iron labelled $\mathrm{MSCs}^{[13]}$.

\section{Prussian blue staining}

The Prussian blue reaction involves treatment of the sections with acid solutions of ferrocyanides. Any ferric ion $(+3)$ present in the tissue combines with ferrocyanide and results in the formation of a bright blue pigment called ferric ferrocyanide or Prussian blue. Iron labelled MSCs injected were detected by Prussian blue staining in the kidney tissue and eosin was used as a counter stain ${ }^{[12]}$.

\section{Microvesicle pellets}

They were prepared for visualization by transmission electron microscope (TEM). MV pellet was gently placed on Formvar-coated copper grids, allowed to adsorb for 45min, and processed for standard uranyl acetate staining. The grids were washed with three changes of PBS and allowed to semidry at room temperature before observation in $\mathrm{TEM}^{[6]}$.

\section{Morphometric study}

The mean area percentage of Ki-67 immunoreactivity was quantified in five images from five non-overlapping fields of each rat using Image-Pro Plus program version 6.0 (Media Cybernetics Inc., Bethesda, Maryland, USA).

\section{Biochemical Investigations}

Blood samples from rats in all groups were drawn from retro-orbital plexus of veins by capillary tubes before injection of glycerol (zero day) and at the $3^{\text {rd }}$ and $10^{\text {th }}$-days after injection. Serum urea and creatinine were measured for all rats throughout the period of the experiment. These measurements were done at Biochemistry Department, Kasr Al-Ainy Medical School. Serum urea and creatinine were measured using the conventional colorimetric method using Quanti Chrom TM assay kits based on the improved Jung and Jaffe methods, respectively (DIUR-500 and DICT-500) $)^{[14]}$.

\section{Statistical analysis}

All the data collected concerning the mean area percentages of Ki-67 immunoreactivity and serum urea and creatinine were recorded and analyzed using IBM SPSS Statistics software for Windows, Version 20 (IBM Corp., Armonk, New York, USA). One-way analysis of variance (ANOVA) with Post Hoc Scheffe's test were used to compare differences among the groups. In each test, 
the data were expressed as the mean $(\mathrm{M})$ value, standard deviation (SD) and differences were considered to be significant (sig) at $p<0.01$

\section{RESULTS}

Bone marrow mesenchymal stem cell
characterization and tracking

MSCs were identified in culture by inverted microscope as spindle-shaped cells (Fig.1-A). The MSCs labeled with iron-oxide injected into the caudal vein were observed in the kidney tissue under light microscope after staining with Prussian blue and counterstained by eosin (Fig. 1-B)

\section{Microvesicles examination by transmission electron microscope}

They appeared having spheroid morphology and their sizes ranged between 50 to $80 \mathrm{~nm}$ (Fig. 1-C).

\section{$H \& E$ stain}

Group I (the control group): The light microscopic examination of subgroups in control group showed nearly the same structures. The renal cortex of control rats showed the renal corpuscles, proximal and distal convoluted tubules (DCTs). The proximal convoluted tubules (PCTs) had narrow lumen and they were lined with pyramidal cells with acidophilic cytoplasm and rounded basally located nuclei. The DCTs were lined with cubical epithelium with light acidophilic cytoplasm and rounded apically situated nuclei. The lumen of the DCTs was wider than that of PCTs (Fig. 2-A).

Group II (affected group): Subgroup IIA: The renal cortex of this subgroup showed vacuolation of the cytoplasm of convoluted tubular cells, flattening of their epithelium lining, dilatation of some tubules, extrusion of the cytoplasm and nuclei into luminal spaces, deeply stained nuclei. Moreover, there were acidophilic hyaline material in tubular lumina. Some renal corpuscles showed shrunken glomeruli and widening of capsular spaces (Fig. 2-B and 2C). Peritubular congestion was also seen (Fig. 2-C).

Subgroup IIB: The renal cortices of this subgroup revealed vacuolation and congestion of the glomeruli, widening of capsular space, vacuolation of the cytoplasm of the tubules, flattening of their epithelium lining, dilatation of the tubules and extrusion of the cytoplasm and nuclei into lumina (Fig. 2-D and 3-A). Pyknotic nuclei and hyaline material in the tubular lumina were also seen (Fig. 3-A).

Group III (stem cell group): The renal cortex of this group showed improvement in the histological structure.
The glomeruli were apparently regular and surrounded by capsular spaces. The renal tubules showed restoration of epithelial lining with increase in the height of epithelium and decrease in vacuolation but few flattened tubular cells were present (Fig. 3-B).

Group IV (conditioned medium group): The renal cortex of this group revealed slight widening of capsular spaces. The renal tubules showed decrease in vacuolation and restoration of epithelial lining with increase height of epithelium but few tubular cells appeared flattened (Fig. 3-C).

Group V (microvesicle group): The renal cortex of this group revealed renal tubules with increased height of epithelium, few vacuolated, flattened cells and few extruded cell debris in the lumina (Fig. 3-D).

\section{Immunohistochemical staining for Ki-67}

Positive immunohistochemical staining for Ki-67 was demonstrated as brown nuclear reaction (index for cell proliferation). The control group showed very weak Ki-67 nuclear immunoreactivity (Fig. 4-A). The affected subgroup IIA and subgroup IIB (3 and 10 days) showed moderate and weak Ki-67 nuclear immune-reactivity respectively (Fig. 4-B and 4-C). The groups III, IV and $\mathrm{V}$ showed intense Ki-67 nuclear immunoreactivity in many tubular cells (Fig. 4-D, 4-E and 4-F) respectively. The glomeruli in all groups showed negative immune reaction.

\section{Morphometric results}

The mean area $\%$ of $\mathrm{Ki}-67$ expression for all groups is presented in table (1) and Fig. 5. There was a significant increase $(\mathrm{P}<0.01)$ in $\mathrm{Ki}-67$ immunoreactivity in groups III, IV and V as compared to control and group II.

\section{EM results}

Group I: The electron microscopic examination of subgroups in control group showed nearly the same structures. Electron microscopic examination of cells lining the proximal tubule showed numerous apical microvilli, multiple elongated mitochondria, and rounded euchromatic nuclei (Fig. 6-A). The cells lining the distal tubules showed apical few short microvilli, basal elongated mitochondria and basal nuclei (Fig. 6-B). The renal filtration barrier of kidney was formed of filtration slits between secondary processes of podocytes, glomerular basement membrane with regular thickness and fenestrated endothelium. Clear foot processes were observed on the surface of renal glomerular basement membrane (Fig. 6-C).

Subgroup IIA: Electron microscopic examination of the cells of proximal convoluted tubules showed 
multiple vacuoles, lysosomes, disrupted microvilli (MV) and extrusion of cytoplasm toward tubular lumen. There were also disorientation of organelles (Fig. 7-A and 7-B). Some nuclei were indented (Fig. 7-C). Cells of distal convoluted tubules revealed vacuoles, disrupted apical border of cells with extrusion of cytoplasm forming debris in the lumina, destructed and vacuolated mitochondria with lysis of their cristae, multiple lysosomes and small nuclei with irregular chromatin distribution (Fig. 8-A). The renal filtration barrier revealed fusion and effacement of the foot processes of podocytes at some sites (Fig. 8-B).

Electron microscopic examination of subgroup IIB revealed poor improvement with persistence of most lesions. The cells of proximal convoluted tubules showed small nuclei with indentation. Some cells showed rarefaction in some parts of the cytoplasm (Fig. 9-A). Microvilli were destructed at some sites with extrusion of the cytoplasm into the tubular lumen (Fig. 9-B). The cells of distal convoluted tubules showed vacuoles and microvilli which were destructed at some sites. Some of the mitochondria were destructed and vacuolated with loss of cristae (Fig. 9-C). The renal filtration barrier of kidney revealed focal thickening in glomerular basement membrane and fusion of some podocytic processes (Fig. 9-D).

Group III: Cells of proximal convoluted tubules showed microvilli at the apical border, nearly normal mitochondria and rounded nuclei (Fig. 10-A). Cells of distal convoluted tubules showed microvilli at the apical border, mitochondria and apparently normal nuclei (Fig. 10-B). The renal filtration barrier showed nearly regular secondary processes of podocytes with filtration slits in between, glomerular basement membrane with apparently regular thickness (Fig. 10-C). Group IV: The cells of proximal convoluted tubules showed microvilli at the apical border, vacuolations, lysosomes, mitochondria and rounded nuclei (Fig. 11-A). Cells of distal convoluted tubules revealed microvilli at the apical border of some cells, other cells had not. There were apparently regular mitochondria (Fig. 11-B). The renal filtration barrier showed secondary processes of podocytes with filtration slits in between, some processes were fused and glomerular basement membrane with apparently regular thickness (Fig.11-C).

Group V: The cells of proximal convoluted tubules showed microvilli at the apical border, some disoriented mitochondria and rounded nuclei (Fig. 12-A). Cells of distal convoluted tubules revealed absence of microvilli at some sites of the apical border and presence at other ones, mitochondria and rounded nuclei (Fig. 12-B).

The renal filtration barrier showed secondary processes of podocytes with filtration slits in between, few processes were fused in some sites glomerular basement membrane with focal thickening (Fig. 12-C).

\section{Biochemical Results:}

The mean serum urea and creatinine levels for all groups were represented in tables (2) and (3) and in line charts (Fig. 13-A and 13-B). There was a significant increase in levels in groups II, III, IV and V in day 3 in comparison to control groups and the levels at the onset of the experiment. The levels remained elevated in group IIB. There was a significant decrease in groups III, IV and $\mathrm{V}$ compared with group II in the $10^{\text {th }}$ day.

Table 1: Showing the mean area \% and SD of Ki-67 immunoreactivity for all groups with comparison between all groups by Post Hoc Scheffe's test.

\begin{tabular}{|c|c|c|c|c|c|c|}
\hline & Group I & Group IIA & Group IIB & Group III & Group IV & w \\
\hline$\%$ Mean area & $0.06 \%$ & $1.25 \%$ & $1.05 \%$ & $3.78 \%$ & $2.87 \%$ & $3.28 \%$ \\
\hline SD & 0.0321 & 0.3910 & 0.2008 & 0.4198 & 0.3003 & 0.3491 \\
\hline $\begin{array}{l}\text { Significance } \\
\text { (sig) at } P<0.01\end{array}$ & $2,3,4,5,6$ & $1,4,5,6$ & $1,4,5,6$ & $1,2,3,5$ & $1,2,3,4$ & $1,2,3$ \\
\hline
\end{tabular}

$1=$ sig \& group I

$2=$ sig \& group IIA

$3=$ sig \& group IIB

$4=$ sig \& group III

$5=\operatorname{sig} \&$ group IV

$6=\operatorname{sig} \&$ group $\mathrm{V}$ 
Table 2: Showing the mean (M) and standard deviation (SD) of serum urea (mg/dl) in all groups with comparison between groups by Post Hoc Scheffe's test (significance at $\mathrm{P}<0.01$ ).

\begin{tabular}{|c|c|c|c|c|c|c|c|c|c|c|}
\hline & \multicolumn{2}{|c|}{ Group I } & \multicolumn{2}{|c|}{ Group IIB } & \multicolumn{2}{|c|}{ Group III } & \multicolumn{2}{|c|}{ Group IV } & \multicolumn{2}{|c|}{ Group V } \\
\hline & M & $\mathrm{SD}$ & M & SD & M & SD & M & $\mathrm{SD}$ & M & $\mathrm{SD}$ \\
\hline Day 0 & 27 & 2.4037 & 29.1 & 2.8460 & 28 & 3.0912 & 28.5 & 3.2059 & 28.3 & 3.1990 \\
\hline Significance & - & & - & & - & & - & & - & \\
\hline Day 3 & 27.4 & 3.1693 & 102.1 & & 102.5 & 8.2091 & 100.1 & 8.8248 & 100.5 & 8.0312 \\
\hline Significance & \multicolumn{2}{|c|}{$2,3,4,5$} & \multicolumn{2}{|c|}{1} & \multicolumn{2}{|c|}{1} & \multicolumn{2}{|c|}{1} & \multicolumn{2}{|c|}{1} \\
\hline Day 10 & 27.7 & 3.0569 & 93 & 5.7155 & 48.9 & 8.0478 & 58.5 & 8.2361 & 55.8 & 9.0774 \\
\hline Significance & \multicolumn{2}{|c|}{$2,3,4,5$} & \multicolumn{2}{|c|}{$1,3,4,5$} & \multicolumn{2}{|c|}{1,2} & \multicolumn{2}{|c|}{1,2} & \multicolumn{2}{|c|}{1,2} \\
\hline
\end{tabular}

$1=$ sig $\&$ group I

$2=$ sig $\&$ group IIB

$3=$ sig \& group III

$4=$ sig \& group IV

$5=$ sig \& group V

Table 3: Showing the mean (M) and standard deviation (SD) of serum creatinine (mg/dl) in all groups with comparison between groups by Post Hoc Scheffe's test (significance at $\mathrm{P}<0.01$ ).

\begin{tabular}{|c|c|c|c|c|c|c|c|c|c|c|}
\hline & \multicolumn{2}{|c|}{ Group I } & \multicolumn{2}{|c|}{ Group IIB } & \multicolumn{2}{|c|}{ Group III } & \multicolumn{2}{|c|}{ Group IV } & \multicolumn{2}{|c|}{ Group V } \\
\hline & M & SD & M & SD & M & SD & M & SD & M & SD \\
\hline Day 0 & 0.47 & 0.0479 & 0.48 & 0.0414 & 0.46 & 0.0433 & 0.48 & 0.0650 & 0.49 & 0.0597 \\
\hline Significance & \multicolumn{2}{|c|}{-} & \multicolumn{2}{|c|}{-} & \multicolumn{2}{|c|}{-} & \multicolumn{2}{|c|}{ - } & \multicolumn{2}{|c|}{-} \\
\hline Day 3 & 0.49 & 0.0579 & 1.01 & 0.0748 & 0.96 & 0.0650 & 1.0 & 0.1192 & 0.99 & 0.0745 \\
\hline Significance & \multicolumn{2}{|c|}{$2,3,4,5$} & \multicolumn{2}{|c|}{1} & \multicolumn{2}{|c|}{1} & \multicolumn{2}{|c|}{1} & \multicolumn{2}{|c|}{1} \\
\hline Day 10 & 0.46 & 0.0531 & 0.89 & 0.0988 & 0.58 & 0.0533 & 0.66 & 0.0420 & 0.60 & 0.0703 \\
\hline Significance & \multicolumn{2}{|c|}{$2,3,4,5$} & \multicolumn{2}{|c|}{$1,3,4,5$} & \multicolumn{2}{|c|}{1,2} & \multicolumn{2}{|c|}{1,2} & \multicolumn{2}{|c|}{1,2} \\
\hline
\end{tabular}

$1=$ sig \& group I

$2=$ sig \& group IIB

$3=$ sig \& group III

4=sig \& group IV

$5=$ sig \& group V 


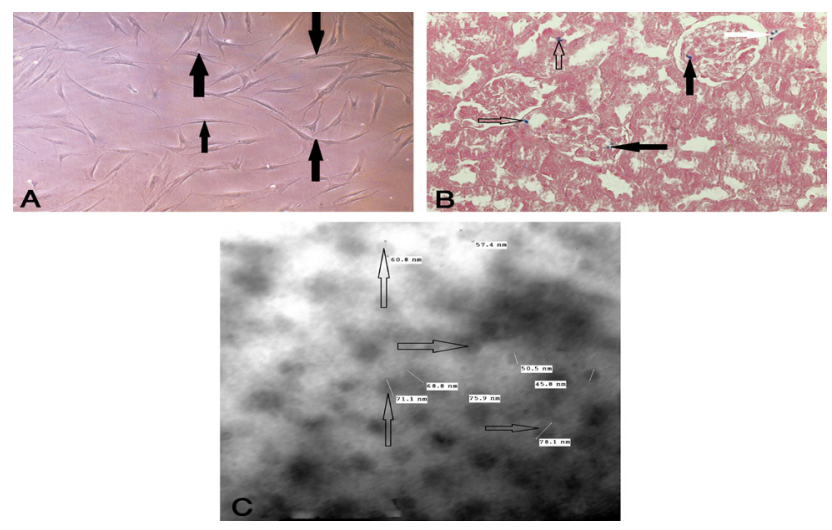

Fig. 1: Photomicrographs showing: A: A primary culture of MSCs on day seven with spindle shape cells (arrows). (Inverted microscope X 400). B: Asection in kidney of a rat from group III (one week after injection of labelled MSCs) with iron labelled MSCs which are present in the glomeruli (black $\uparrow$ ), in the interstitial tissue (white $\uparrow$ ) and in the wall of the tubules (hollow arrows). (Prussian blue and eosin counter stain X 400). C: Purified microvesicles showing the microvesicles (arrows) with spheroid appearance. Their sizes measured between $50 \mathrm{~nm}$ and $80 \mathrm{~nm}$.

(EM X 146000)

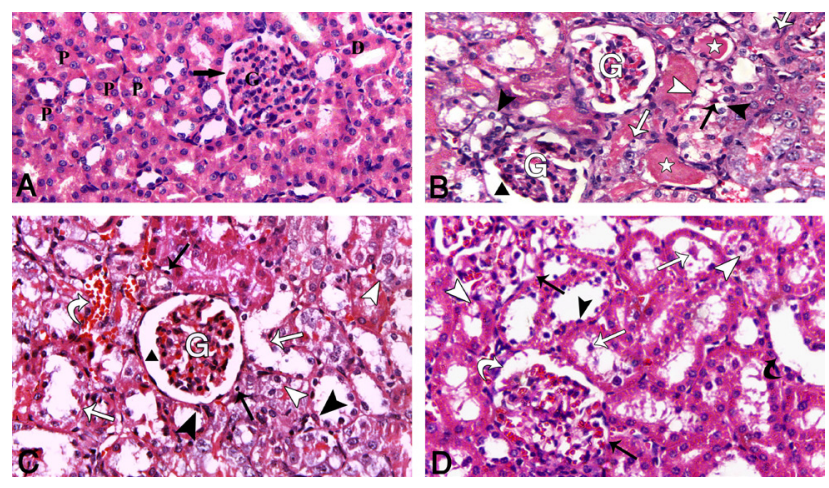

Fig. 2: Photomicrographs of sections of kidneys of rats stained by (H\&E X 400) showing: A: A section from control rat illustrating renal corpuscle formed of glomerulus $(\mathrm{G})$ and Bowman's capsule with capsular space $(\uparrow)$, proximal convoluted tubules $(\mathrm{P})$ and distal convoluted tubules (D). B: A section of a rat from group IIA illustrating shrinkage of the glomeruli $(\mathrm{G})$ with widening of the capsular space (black triangle), vacuolation of the cytoplasm of the tubular cells (black arrow heads), flattening of the epithelium lining the tubules (white arrow head), extrusion of the cytoplasm and nuclei into the lumen (black $\uparrow$ ) and pyknotic nucleus (white $\uparrow)$. Notice the presence of hyaline material in the lumen (stars). C: A section of a rat from subgroup IIA revealing shrinkage of the glomerulus $(\mathrm{G})$ with widening of the capsular space (black triangle), vacuolation of the cytoplasm of the tubular cells (white arrow heads), flattening of the epithelium lining the tubules (black arrow heads), dilatation of the tubules (white $\uparrow$ ), pyknotic nucleus (black $\uparrow$ ) and peritubular congestion (bent arrow). D: A section of a rat from group IIB revealing vacuolation and congestion of the glomeruli (black $\uparrow$ ), widening of capsular space (white bent arrow) vacuolation of the cytoplasm of the tubules (white arrow heads), flattening of the epithelium lining the tubules (black arrow head), dilatation of the tubules (black bent arrow) and extrusion of the cytoplasm and nuclei into the lumen (white $\uparrow$ ).

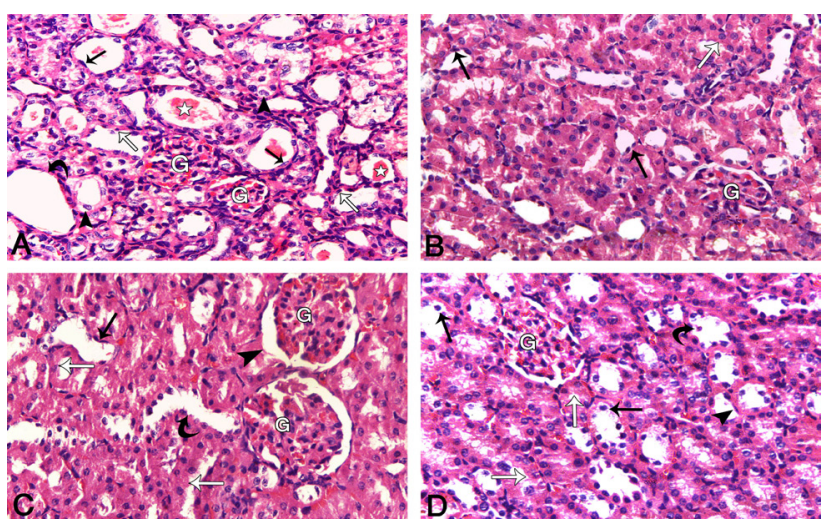

Fig. 3: Photomicrographs of sections of kidneys of rats (H\&E X 400) showing: A: A section of a rat from group IIB illustrating the glomeruli $(\mathrm{G})$, vacoulation of the cytoplasm of the tubules (black arrow heads), flattening of the epithelium lining the tubules (black $\uparrow$ ), dilatation of the tubules (bent arrow), pyknotic nucleus (white $\uparrow$ ) and presence of hyaline material in the lumen (stars). B: A section of a rat from group III (stem cell group) having renal corpuscle formed of glomerulus $(\mathrm{G})$ surrounded by capsular space. The renal tubules show restoration of epithelial lining with increase in the height of epithelium (white $\uparrow$ ) but few tubular cells appear flattened (black $\uparrow$ ). C: A section of a rat from group IV (conditioned medium group) illustrating renal corpuscles with glomeruli $(\mathrm{G})$ surrounded by slight widening of capsular spaces (arrow head). The renal tubules show restoration of epithelial lining with increase in the height of epithelium (white $\uparrow$ ) but few tubular cells appear flattened (black $\uparrow$ ). There are few tubular dilatations (bent arrow). D: A section of a rat from group $\mathrm{V}$ (microvesicle group) showing renal corpuscle with glomerulus $(\mathrm{G})$ surrounded by capsular space. The renal tubules show restoration of the height of epithelium (white $\uparrow$ ), few vacuolated (black $\uparrow$ ) and flattened (arrow head) tubular cells. Extruded cell debris (bent arrow) can be seen.
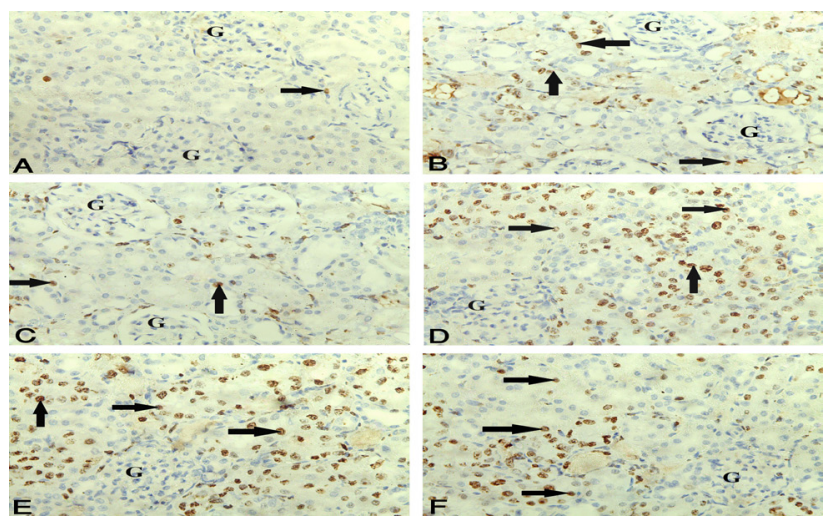

Fig. 4: Photomicrographs of sections of kidneys of rats (Immunohistochemistry stain for Ki-67 X 400) showing immunopositive nuclei in the renal tubular cells $(\uparrow)$ and negative immunoreactivity in the glomeruli (G): A: A section of a rat from control group with very few number of immunopositive nuclei. B: A section of a rat from group IIA (affected group) showing an apparent increase in immunopositive nuclei. C: A section of a rat from group IIB showing some immunopositive nuclei. D, E and F: revealed large number of immunopositive nuclei in groups III, IV and V. 


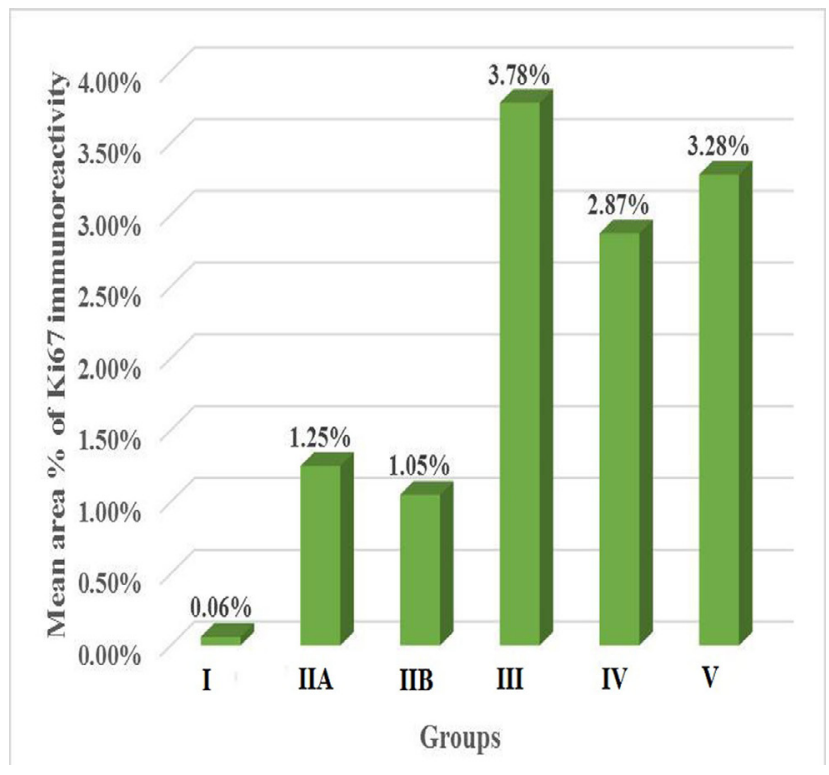

Fig. 5: Showing a histogram of the mean area $\%$ of Ki-67 immunoreactivity in groups I, IIA, IIB, III, IV and V.

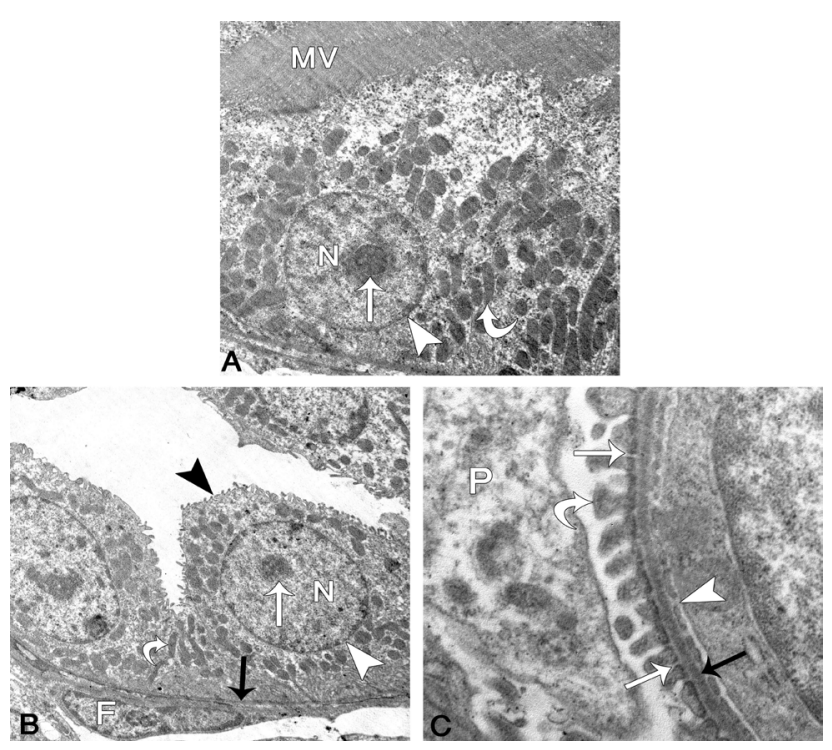

Fig. 6: EM micrographs of a kidney of control rat showing:

A: A proximal convoluted tubule with microvilli at the apical border (MV), numerous elongated mitochondria (bent arrow), rounded nucleus $(\mathrm{N})$ with prominent nucleolus $(\uparrow)$ and regular nuclear envelope (arrow head). X 8780. B: A distal convoluted tubule with few short microvilli at the apical border (arrow head), numerous elongated mitochondria (curved arrow) and nucleus $(\mathrm{N})$ with normal distribution of chromatin, prominent nucleolus (white $\uparrow$ ) and regular nuclear envelope (arrow head). There is an interstitial fibroblast (F). The black arrow points to the basement membrane of the tubular cells. X 8780. C: Filtration barrier revealing podocyte $(\mathrm{P})$ with regular secondary processes (curved arrow) and filtration slits in between (white $\uparrow$ ), glomerular basement membrane with regular thickness (black $\uparrow$ ) and fenestrated endothelium (arrow head). X 46500

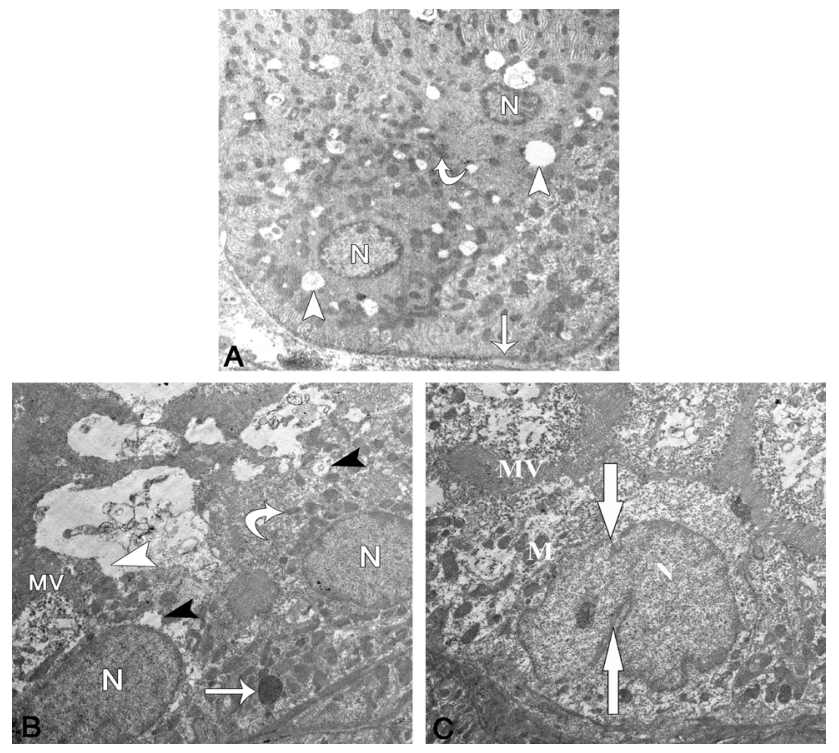

Fig. 7: EM micrographs of a proximal convoluted tubule of kidney of a rat from group IIA (X 8780) showing: A: A disorientation of organelles, multiple vacuoles (arrow heads), small mitochondria (curved arrow) and two small shrunken nuclei $(\mathrm{N})$. The white arrow points to the basement membrane. B: A lysosome $(\uparrow)$, vacuoles (black arrow heads), destructed microvilli (MV) at some sites with extrusion of cytoplasm to the lumen (white arrow head), mitochondria (bent arrow) and nuclei $(\mathrm{N})$. C: Disturbed microvilli (MV), mitochondria (M) and indented nucleus $(\uparrow)$.

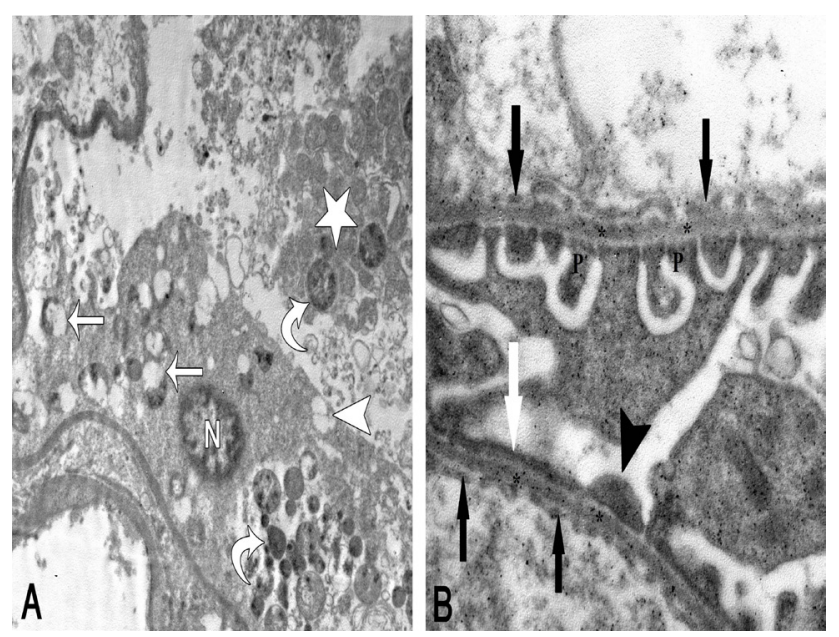

Fig. 8: EM micrographs of a kidney of a rat from group IIA showing: A: A distal convoluted tubule with vacuoles (arrow head), disrupted apical border with extrusion of cytoplasm forming debris in the lumen (white star), rounded, destructed and vacuolated mitochondria with lyses of their cristae $(\uparrow)$, multiple lysosomes (bent arrows) and small nucleus with irregular chromatin distribution $(\mathrm{N})$. X 8780. B: A renal filtration barrier consisting of secondary processes of podocytes $(\mathrm{P})$ which are effaced at some sites (white $\uparrow$ ) and fused in other site (arrow head), glomerular basement membrane (stars) and endothelium (black $\uparrow$ ). X 46500 


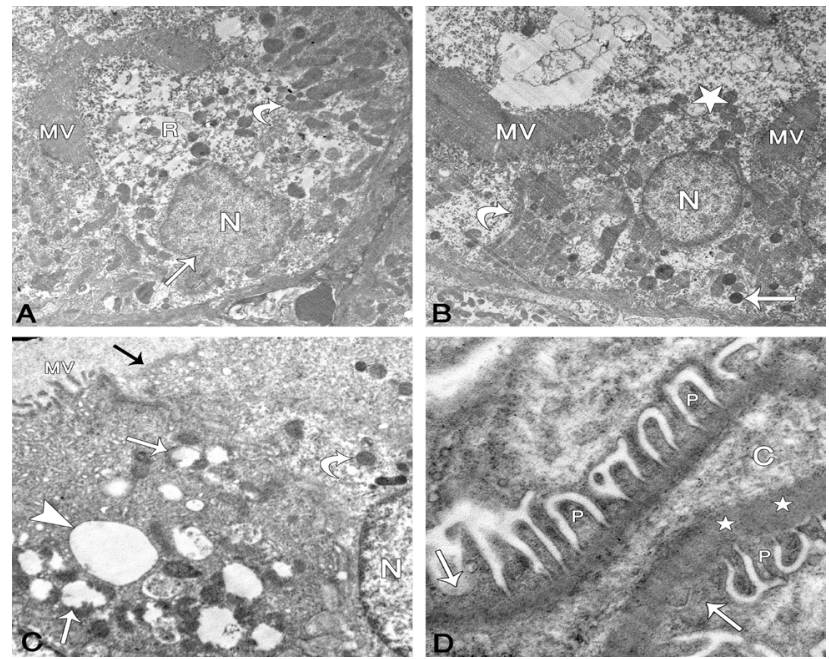

Fig. 9: EM micrographs of a kidney of a rat from group IIB showing: A: A proximal convoluted tubule with microvilli (MV), mitochondria (bent arrow) and a nucleus (N) with some indentation $(\uparrow)$. There is rarefaction of some parts of the cytoplasm (R) X 8780. B: A proximal convoluted tubule with lysosomes $(\uparrow)$, microvilli (MV) which are destructed at some sites with extrusion of the cytoplasm forming debris in the lumen of the tubule (star), mitochondria (bent arrow) and nucleus (N) X 8780. C: A distal convoluted tubule illustrating vacuoles (arrow head), microvilli (MV) which are destructed at some sites (black $\uparrow)$, mitochondria (bent arrow), and a part of nucleus $(\mathrm{N})$. Some of the mitochondria are destructed and vacuolated with loss of cristae (white $\uparrow$ ). X 17500. D: Renal filtration barrier consisting of secondary processes of podocytes $(\mathrm{P})$ which appear fused at some parts $(\uparrow)$, focal thickening of glomerular basement membrane (stars) and capillary lumen (C). X 46500

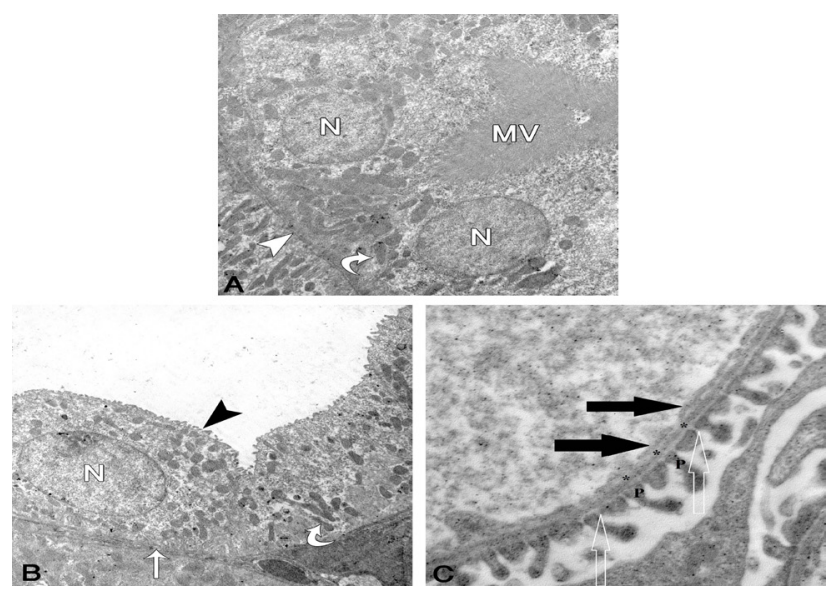

Fig. 10: EM micrographs of a kidney of a rat from stem cell group showing: A: A proximal convoluted tubule with microvilli at the apical border (MV), mitochondria (bent arrow), rounded nuclei (N) and the tubular basement membrane (arrow head). X 8780 B: A distal convoluted tubule revealing short microvilli at the apical border (arrow head), mitochondria (bent arrow), nucleus $(\mathrm{N})$ and basement membrane of cells $(\uparrow)$. X 8780. C: A renal filtration barrier consisting of secondary processes of podocyte (P) with filtration slits in between (white $\uparrow$ ), glomerular basement membrane with apparently regular thickness (stars) and fenestrated endothelium (black $\uparrow$ ). X 46500

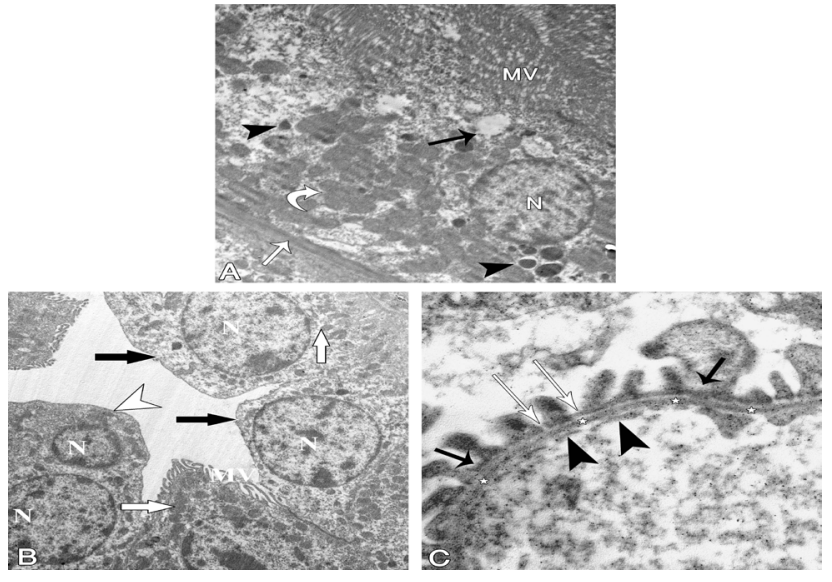

Fig. 11: EM micrographs of a kidney of a rat from conditioned medium group showing: A: A cell of proximal convoluted tubule illustrating microvilli at the apical border (MV), vacuolations (black $\uparrow$ ), lysosomes (arrow heads), mitochondria (bent arrow), rounded nucleus $(\mathrm{N})$ and basement membrane (white $\uparrow$ ). X 8780 B: A distal convoluted tubule with some cells having microvilli at the apical border (MV), other cells have not (black $\uparrow$ ), mitochondria (white $\uparrow$ ) and nuclei $(\mathrm{N})$. Note the binucleated cell (arrow head). X 8780. C: Renal filtration barrier consisting of secondary processes of podocytes with filtration slits in between (white $\uparrow$ ), some processes are fused (black $\uparrow$ ), glomerular basement membrane with apparently regular thickness (stars) and fenestrated endothelium (arrow heads). X 46500
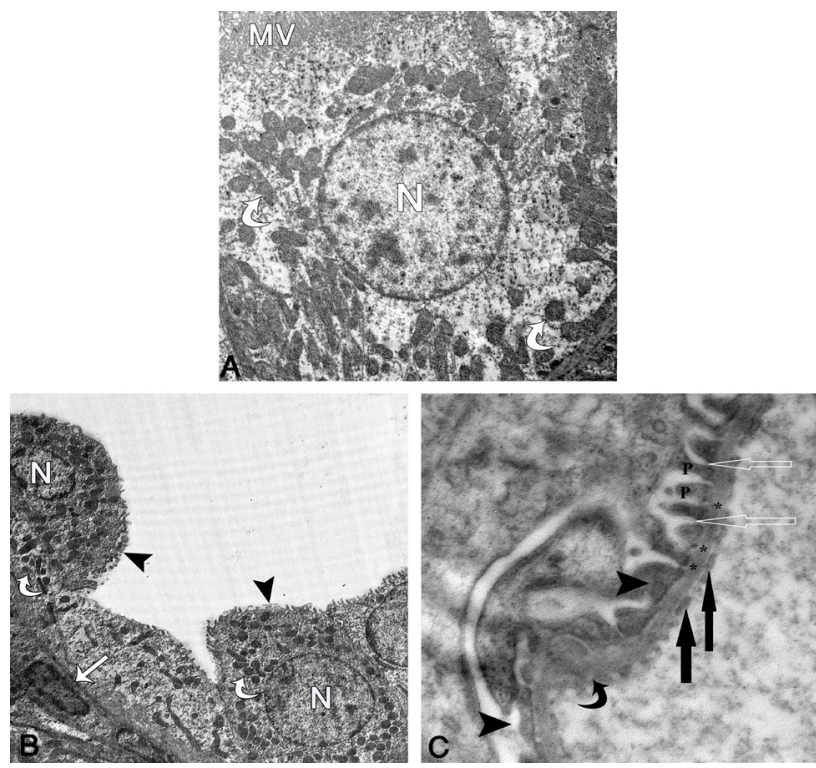

Fig. 12: EM micrographs of a kidney of a rat from microvesicle group showing: A: A proximal convoluted tubule with microvilli at the apical border (MV), disoriented mitochondria (bent arrow) and rounded nucleus $(\mathrm{N})$. $\quad$ X 8780 B: A distal convoluted tubule illustrating few microvilli at the apical border (arrow heads), mitochondria (bent arrows) rounded nuclei $(\mathrm{N})$ and interstitial fibroblast $(\uparrow) . \quad$ X 8780 $\mathrm{C}$ : Renal filtration barrier consisting of secondary processes of podocytes $(\mathrm{P})$ with filtration slits in between (white $\uparrow$ ), some processes are fused in some sites (arrow heads), glomerular basement membrane (stars) with an area with focal thickening (bent arrow) and fenestrated endothelium (black $\uparrow$ ). $\quad$ X 46500 

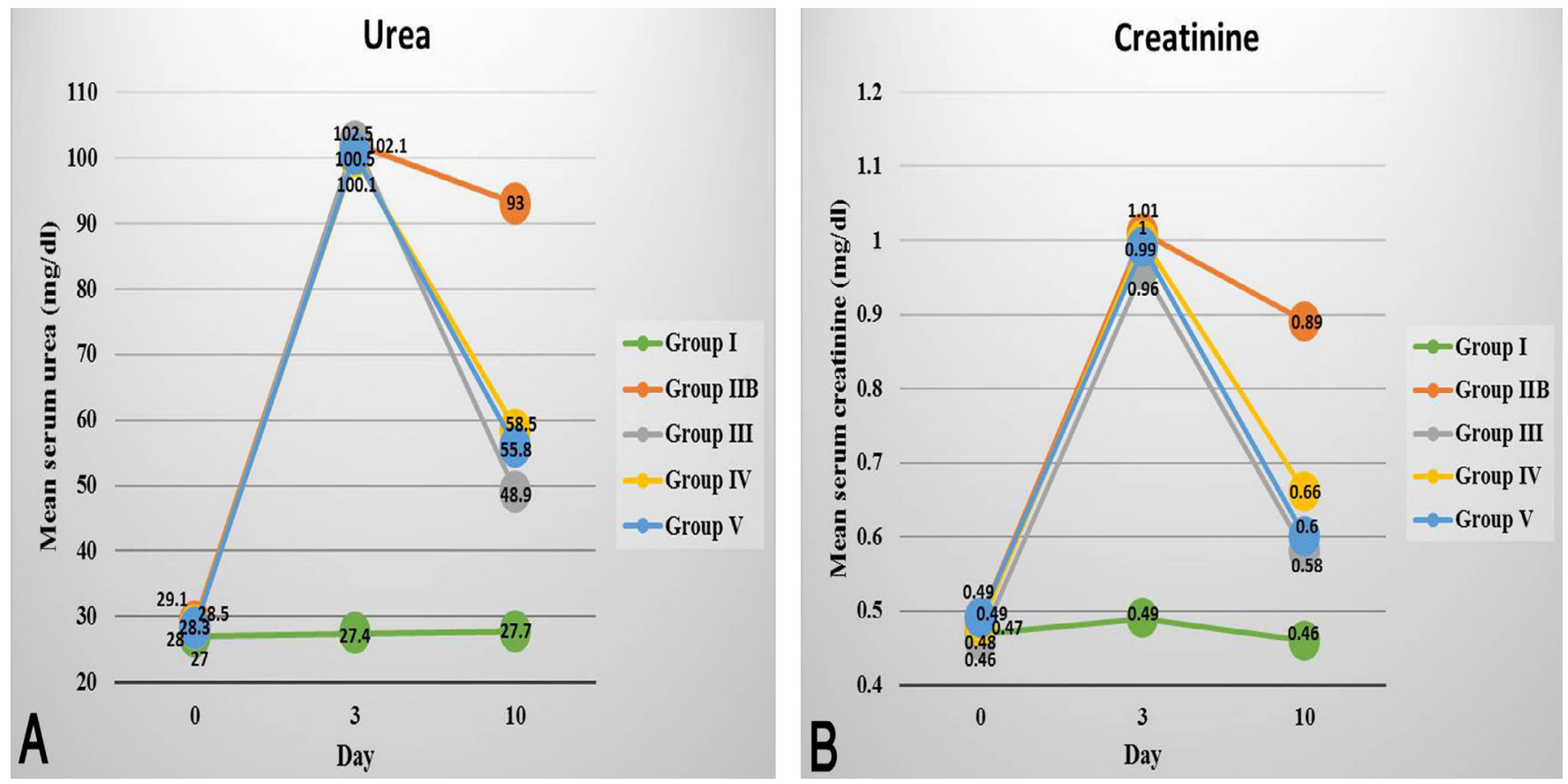

Fig. 13: Line charts showing the mean serum levels of urea (A) and creatinine (B) $(\mathrm{mg} / \mathrm{dl})$ at days 0,3 and 10 for all groups.

\section{DISCUSSION}

Acute kidney injury has recently been recognized as a major health problem. Hospital mortality rates in intensive care unit patients with AKI could reach 50\% -70\%. AKI is associated with high cost of medical care due to lack of effective therapeutic strategies and no effective pharmacologic intervention ${ }^{[15]}$.

The current study was designed to evaluate the ameliorative effect of MSCs, CM and MVs on experimentally induced acute renal injury. Hypertonic glycerol injection into rats is one of the most widely used models of experimental AKI. It is well known as animal model of rhabdomyolysis ${ }^{[2]}$.

In this study, rats in group I showed normal histological architecture in the sections examined by LM and EM. Ki-67 immmunostained sections revealed very few number of immunopositive nuclei in the renal tissue. The kidney functions tested by serum urea and creatinine levels were normal.

Rats in group II that were injected by glycerol revealed tubular damage mainly affecting proximal and distal convoluted tubules. Similar findings have been reported by other investigators ${ }^{[16,17]}$ who found that glycerol induced tubular dilatation, vacuolation, tubular necrotic lysis and cellular micro-debris into the tubular lumina of the proximal and distal convoluted tubules.

Some of the glomeruli in group II showed shrinkage with widening of the capsular space and some of them were congested with blood. These findings were consistent with other studies ${ }^{[18]}$.
On the other hand, some investigators ${ }^{[17]}$ reported that there were mainly tubular damage and no glomerular affection in glycerol induced AKI.

The EM examination of renal tubules from group II showed damage of proximal and distal convoluted tubules in the form of disoriented or disorganized mitochondria with disrupted cristae, vacuolization of the renal tubules and loss of microvilli. These findings are consistent with the studies of other researchers ${ }^{[1]}$ who reported tubular damage, disorganized mitochondria, vacuolization of the renal tubules and loss of microvilli in glycerol induced AKI. Moreover, another study ${ }^{[19]}$ showed swollen partially destructed mitochondria in such conditions.

Some of the glomeruli showed irregular thickening of the glomerular basement membrane and fusion of secondary processes of podocytes. This was consistent with the study of Shalaan and Khalii ${ }^{[20]}$ who stated that secondary processes of podocytes showed some thickening and fusion and the glomerular basement membrane was moderately thickened and disrupted in glycerol induced AKI.

It was seen that the observed lesions in the blood renal barrier and loss of microvilli of proximal convoluted tubules might affect the protein reabsorption from the urinary filtrates. So the protein might pass to the renal tubules, which were detected as hyaline casts in the lumen of the renal tubules by LM.

These light and electron microscopic findings were present in subgroup IIA in which the animals were sacrificed three days after glycerol injection and persisted in subgroup IIB in which the animals were sacrificed ten days after glycerol injection indicating poor improvement. 
This was consistent with the other studies ${ }^{[21]}$ which showed persistence of pathological findings after glycerol administration without treatment and apparent spontaneous healing occurred after three weeks.

The pathogenesis of glycerol-induced AKI is a complex process. Oxidative stress, apoptosis and inflammation are implicated ${ }^{[16-22]}$. Myoglobin, an iron-containing muscle cell protein, plays an important role in rhabdomyolysis-induced AKI. The mechanism involves three different pathways: tubular obstruction, tubular damage caused by oxidant injury and renal vasoconstriction. Inflammation is known as a cause of rhabdomyolysis-induced AKI. Muscle fibers damaged during the process of rhabdomyolysis release immunostimulatory molecules that activate the production of pro-inflammatory cytokines such as interleukin- 6 and tumor necrosis factor- $\alpha$, thus leading to kidney injury ${ }^{[16]}$.

The immunopositive nuclei for Ki-67 in group I were very few, while subgroup IIA revealed some increase in number of nuclei in the renal tubules. Morphometrical and statistical studies detected increase in mean area percentage of Ki-67 immunoreactivity in subgroup IIA in comparison to control group. This might be explained by the fact that under normal circumstances the tubular epithelial cells have a slow rate of proliferation, this slow rate changes after an injury to be a high rate of cell division and this is in accordance with Humphreys and Bonventre $^{[23]}$ who reported that organs, such as kidney and lung, have a very low rate of cellular turnover but are capable of proliferating and repairing after an injury.

Additionally, Bonventre and Yang ${ }^{[24]}$ stated that this low rate of turnover changes dramatically after an ischemic or toxic insult, when there is a marked increase in cell death by necrosis and apoptosis. The living cells undergo a high rate of mitosis to replace these cells. The number of immunopositive nuclei in subgroup IIB slightly decreased than subgroup IIA. The mean area percentage of Ki-67 immunoreactivity in subgroup IIB was less than subgroup IIA but still more than the control. This is consistent with the findings in the studies of some investigators ${ }^{[22,25]}$ which showed increase in number of proliferating nuclei immediately after glycerol induced AKI in comparison to control group then decreased after few days.

The levels of serum urea and creatinine were elevated in group II and persisted elevated indicating affection of kidney function. The kidney dysfunction was reported also in other studies after glycerol injection ${ }^{[17,19,26]}$.

After AKI, renal tubule cells show a tendency to spontaneous regeneration, but in severe cases complete repair is not achieved. It remains controversial whether stem cells populations existing within the adult kidney contribute to the regeneration of renal tubule cells after injury or not. Advanced reports stated that dedifferentiated cells from renal tubule are responsible for the repair of the degenerated tubules. Transplanted stem cells could secrete paracrine factors and supply cell materials that help the renal tubules regeneration. For example, transplanted stem cells could secrete paracrine factors that help the regeneration of renal tubules and provide additional cell materials for the kidney regeneration. A paracrine effect is more likely if the epithelial dedifferentiation of renal tubular cells is the main mechanism for recovery from AKI. However, the replacement of injured renal tubular cells is can also occur ${ }^{[27]}$. Currently, MSCs have been known as favorable tool for therapy in clinic, due to their several advantages such as extensive in vitro expansion, self renewal, engraftment capacity, immunomodulation characters, multi-lineages differentiation potential and few ethical concerns are needed for their use ${ }^{[28]}$.

The present study revealed that the animals injected with MSCs showed amelioration of the histological changes that occurred in the kidney. There were decrease in vacuolation and increase in the height of epithelium and there were no casts as detected by examination of H\&E stained sections. EM examination also showed amelioration of structure of proximal and distal convoluted tubules and renal filtration barrier. Also Ki-67 stained sections showed intense immune reaction in group III in comparison to control group and group II indicating increased proliferation of cells. Moreover, kidney function tests improved. The levels of urea and creatinine decreased in comparison to group II.

The previous findings were consistent with other studies ${ }^{[25,29]}$ which revealed that MSCs ameliorated renal injury as tubular necrosis and luminal casts in glycerol induced AKI. Also they promoted proliferation as detected by PCNA immunostaining and ameliorated kidney functions. Moreover, other studies ${ }^{[5,6,30]}$ showed that MSCs ameliorated kidney injuries, promoted renal proliferation and improved kidney functions in other forms of AKI like gentamicin, cisplatin and ischemia reperfusion induced kidney injuries.

Therefore, exogenous MSCs have been considered as one of the new effective strategies for AKI. Although the mechanisms responsible for their protective and regenerative effects are incompletely understood, antiinflammatory/ immunoregulatory properties of MSCs and decreased mitochondrial apoptosis pathway are recognized as important mechanisms ${ }^{[29,31]}$.

The rats treated by $\mathrm{CM}$ showed improvement in the morphology of kidney as detected by H\&E stained sections which showed decrease in vacuolation of the cells. Also electron microscopic examination showed improvement in the structure of tubules and renal filtration barrier with few residual lesions. Also Ki-67 stained sections showed intense immune reaction in group IV in comparison to control group and group II indicating increased proliferation of cells. Kidney functions in group IV were also ameliorated as the levels of urea and creatinine decreased in comparison to group II but were still high as compared to control group. 
This is consistent with other studies that detected the effectiveness of CM and MSCs soluble factors in treating some different models of AKI. Other investigators ${ }^{[6,32]}$ found that the conditioned medium was able to minimize the deleterious effects caused by gentamicin and enhanced renal proliferation. Also the study of Abouelkheir et al. ${ }^{[5]}$ indicated that MSCs and their conditioned medium ameliorated the pathological changes, enhanced kidney functions, decreased apoptosis and promoted proliferation detected by Ki-67 immunostaining in acute kidney injury induced by cisplatin. They found that MSCs therapy was associated with the appearance of adipocytes and osteoblast-like cells. These maldifferntiated cells were absent in CM group indicating that the medium may be more safe than the MSCs and may replace them in treating injuries. Moreover, it was reported ${ }^{[33]}$ that induced pluripotent stem cell-derived conditioned medium attenuated AKI by down-regulating the oxidative stressrelated pathway in ischemia-reperfusion induced AKI in rats.

In the contrary, other researchers ${ }^{[34]}$ found that the conditioned medium of MSCs could not protect against kidney failure in terms of serum urea and creatinine and histopathologic examinations in cisplatin induced acute kidney injury in rats. Also it was found ${ }^{[35]}$ that MSCs, not $\mathrm{CM}$, contribute to kidney repair after ischemia-reperfusion injury.

The animals injected by MVs showed amelioration in the morphology of renal tissue in the form of a decrease in vacuolation as detected by H\&E stained sections. Also electron microscopic examination showed improvement in the structure of tubules and renal barrier with few residual lesions. Ki-67 stained sections showed intense immune reaction in group $\mathrm{V}$ in comparison to groups I and II indicating increased proliferation of cells. The kidney functions also improved in comparison to group II but were still high as compared to control group.

These results were in accordance with several studies. Some investigators ${ }^{[36]}$ stated that MVs improved renal function and reduced the extent of kidney injury. A single administration of MVs immediately following ischemiareperfusion-injury-induced $\mathrm{AKI}^{[37]}$ or cisplatin alleviated inflammation, decreased renal cell apoptosis, and increased proliferation of the renal epithelial cells. In addition, multiple injections of MVs led to further improved renal function and morphology, abrogated renal fibrosis, and decreased mortality ${ }^{[38]}$.

Different pathways demonstrate the ability of MVs to modulate simultaneously several genes to stimulate renal repair and/or regeneration. MVs stimulated renal repair through inducing the expression of the antiapoptotic genes BCL-2, BCL-XL and BIRC-8 in renal tubular epithelial cells while simultaneously downregulating the proapoptotic genes LTA, CASP-1 and CASP-8. Also, MVs shuttled RNA associated with control of transcription, proliferation, and immune regulation to the damaged epithelium. Furthermore, MVs stimulated renal cell proliferation by inducing the phosphorylation followed by activation of extracellular regulated kinase ${ }^{[39]}$.

Moreover, it was stated ${ }^{[40]}$ that MVs modulated microRNAs in renal tubular cells and inhibited ATP depletion injury. They alleviated renal ischemic reperfusion injury and enhanced angiogenesis in rats. Another study ${ }^{[41]}$ showed that MVs are enriched in certain molecules, including heatshock proteins, signal transduction proteins, adhesion molecules, membrane trafficking molecules, cytoskeleton molecules, cytoplasmic enzymes, and importantly, functional mRNAs and microRNAs. Their role in vivo may be related to cell to cell communication and to proteins and RNAs exchange among cells both locally and at distance.

\section{CONCLUSION}

Mesenchymal stem cells, their CM and MVs enhanced healing of experimentally induced AKI with little differences in their effectiveness. However, stem cell group revealed mild increase in renal tubular cell proliferation than MVs and conditioned medium. The CM and MVs can be used instead of stem cells in treating tissue injuries and further studies for prolonged periods should be done to show their effectiveness on the long run.

\section{CONFLICT OF INTEREST}

There are no conflicts of interest

\section{REFERENCES}

1. Zuk A, Bonventre JV, Acute Kidney Injury. Annu Rev Med 2016; 67: 293- 307.

2. Singh, PA, Junemann, A, Muthuraman A, Jaggi SA, Singh N, Grover K, Dhawan R. Animal models of acute renal failure. Pharmacol Rep 2012; 64: $31-44$.

3. Bianco P, Cao X, Frenette PS, Mao JJ, Robey PG, Simmons PJ, Wang CU. The meaning, the sense and the significance: translating the science of mesenchymal stem cells into medicine. Nat Med 2013; 19 (1): 35- 42.

4. Figeac F, LesaultPF, Le CozO, Damy T, Souktani R, Trebeau C, Schmitt A, Ribot J, Mounier R, Guguin A, Manier C, Surenaud M, Hittinger L, DuboisRandé J, Rodriguez A. Nanotubular crosstalk with distressed cardiomyocytes stimulates the paracrine repair function of mesenchymal stem cells. Stem Cells 2014; 32: 216- 230.

5. Abouelkheir M, El-Tantawy DA, Saad MA, Abdelrahman KM, Sobh MA, Lotfy A, Sobh MA. Mesenchymal stem cells versus their conditioned 
medium in the treatment of cisplatin-induced acute kidney injury: evaluation of efficacy and cellular side effects. Int J Clin Exp Med 2016; 9 (12): 23222- 23234.

6. Reis LA, Borges FT, Simo es MJ, Borges AA, Sinigaglia CR, Schor N. Bone marrow-derived mesenchymal stem cells repaired but did not prevent gentamicin-induced acute kidney injury through paracrine effects in rats. PLOS ONE 2012; 7 (9): 1- 11 .

7. Quesenberry PJ, Goldberg LR, Aliotta JM, Dooner MS, Pereira MG, Wen S, Camussi G. Cellular phenotype and extracellular vesicles: basic and clinical considerations. Stem Cells Dev 2014; 23: 1429 -1436.

8. Kim JH, Lee SS, Jung MH, Yeo HD, Kim HJ, Yang JI, Roh GS, Chang SH and Park DJ. $\mathrm{N}$-acetylcysteine attenuates glycerol-induced acute kidney injury by regulating MAPKs and Bcl-2 family proteins. Nephrol Dial Transplant 2010; 25: 1435- 1443.

9. El Said HE, Gabr HM, Ammar RI. The effect of human bone marrow mesenchymal stem cells on diabetic heart failure rats. Life Sci J 2013; 10 (1): 3413 -3425.

10. Momen-Heravi F, Balaj L, Aliann S, Trachtenberg AJ, Hochberg FH, Skog J, Kuo WP. Impact of biofluid viscosity on size and sedimentation efficiency of the isolated microvesicles. Front Physio 2012; 3 (162): 1- 6.

11. Bruno S, Grange C, Deregibus MC, Calogero RA, Saviozzi S, Collino F, Morando L, Busca A, Falda M, Bussolati B, Tetta C, Camussi G. Mesenchymal stem cell-derived microvesicles protect against acute tubular injury. J Am Soc Nephrol 2009; 2 (5): 1053- 1067.

12. Suvarna SK, Layton C, Bancroft JD, Theory and Practice of Histological Techniques. $7^{\text {th }}$ ed., ch10. Philadelphia, Churchill Livingstone 2013; 172538-493,434-382,186 and 239- 270.

13. Riegler J, Liew A, Hynes SO, Ortega D, O'Brien T, Day RM, Richards T, Sharif F, Pankhurst QA, Lythgoe MF. Superparamagnetic iron oxide nanoparticle targeting of MSCs in vascular injury. Biomaterials 2013; 34 (8): 1987 -1994.

14. Abdel Aziz MT, Wassef MA, Rashed LA, Mhfouz S, Omar N, Elsebaie MM. Mesenchymal Stem Cells Therapy in Acute Renal Failure: Possible
Role of Hepatocyte Growth Factor. J Stem Cell Res Ther 2011; 1: 109- 115 .

15. Rewa O, Bagshaw SM. Acute kidney injuryepidemiology, outcomes and economics. Nat Rev Nephrol 2014; 10: 193- 207.

16. Nara K, Yajima D, Nagasawa S, Abe1 H, Hoshioka $\mathrm{Y}$, Iwase $\mathrm{H}$. Evaluations of lipid peroxidation and inflammation in short-term glycerol-induced acute kidney injury in rats. Clin Exper Pharmacol Physiol 2016; 43: 1080- 1086.

17. Al Asmari AK, Al Sadoon KT, Obaid AA, Yesunayagam D, Tariq M. Protective effect of quinacrine against glycerol-induced acute kidney injury in rats. BMC Nephrology 2017; 18: 41- 50.

18. Yadav D, Kumar M, Tripathi YB. Methanolic extract of tubers of Pueraria tuberosa Linn. ameliorates glycerol induced acute kidney injury in rats. J. Chem and Pharma Res 2016, 8(2): 133- 139.

19. Huang D, Wang C, Meng Q, Liu Z, Huo X, Sun H, Yang S, Ma X, Pengab J, Liu K. Protective effects of formononetin against rhabdomyolysis-induced acute kidney injury by upregulating $\mathrm{Nrf} 2$ in vivo and in vitro. RSC Adv 2016; 6: 110874 -110883.

20. Shalaan AAM, Khalil MS. Histological and immunohistochemical study of the postulated protective effect of L-Arginine on glycerol induced acute renal failure in adult male albino rats. Egypt J Histol 2009; 32(2): 333 -345.

21. Hauser PV, De Fazio R, Bruno S, Sdei S, Grange C, Bussolati B, Benedetto C, Camussi G. Stem cells derived from human amniotic fluid contribute to acute kidney injury recovery. Am J Pathol 2010; 177 (4): 2011 -2020.

22. Korrapati MC, Shaner BE, Schnellmann RG. Recovery from glycerol-induced acute kidney injury is accelerated by suramin. J Pharmacol Exp Ther. 2012; 341(1): 126- 136.

23. Humphreys BD, Bonventre JV. Mesenchymal stem cells in acute kidney injury. Annu Rev Med 2008; 59: $311-325$.

24. Bonventre JV and Yang L. Cellular pathophysiology of ischemic acute kidney injury. J Clin Invest 2011; 121(11): 4210 -4221.

25. Geng $\mathrm{Y}$, Zhang L Fu B, Zhang J, Hong Q, Hu J, Li D, Luo C, Cui S, Zhu F, Chen 
X. Mesenchymal stem cells ameliorate rhabdomyolysis-induced acute kidney injury via the activation of M2 macrophages. Stem Cell Res Ther 2014, 5(80): 1 -14.

26. Navarro AR, Carril M, Padro D, Guerrero-Hue M, Tarín C, Samaniego R, Cannata P, Cano A, Villalobos JMA, Sevillano AM, Yuste C, Gutiérrez E, Praga M, Egido J, Moreno JA. CD163macrophages are involved in rhabdomyolysisinduced kidney Injury and may be detected by MRI with Targeted gold-coated iron oxide nanoparticles. Theranostics 2016; 6(6): 896- 914.

27. Kramann R, Kusaba T, Humphreys BD. Who regenerates the kidney tubule? Nephrol Dial Transplant. 2015;30(6): 903-910.

28. Prasajak P, Leeanansaksiri W. Mesenchymal stem cells: current clinical applications and therapeutic potential in liver diseases. J Bone Marrow Res 2014; 2 (1): 137- 145.

29. Geng X, Hong Q, Wang W, Zheng W, Li O, Cai $\mathrm{G}$, Chen X, Wu D Biological membrane-packed mesenchymal stem cells treat acute kidney disease by ameliorating mitochondrial- related apoptosis. Sci Rep 2017; 7 (41136):1- 12

30. Hu J, Zhang L, Wang N, Ding R, Cui S, Zhu F, Xie Y, Sun X, Wu D, Hong Q, Li Q, Shi S, Liu $\mathrm{X}$, Chen X. Mesenchymal stem cells attenuate ischemic acute kidney injury by inducing regulatory $\mathrm{T}$ cells through splenocyte interactions. Kid Inter 2013; 84: 521- 531.

31. Du T, Zhu YJ. The regulation of inflammatory mediators in acute Kidney injury via exogenous mesenchymal stem cells. Med Inflamm 2014; 26169: 1 -11.

32. Abedi A, Azarnia M, zahvarehy MJ, foroutan T, Golestani S. Effect of different times of intraperitoneal injections of human bone marrow mesenchymal stem cell conditioned medium on gentamicin-induced acute kdney injury. Miscellaneus 2016; 13 (3): 2707 -2716.

33. Tarng DC, Tseng WC, Lee PY, Chiou SH, Hsieh SL. Induced pluripotent stem cell-Derived conditioned medium attenuates acute kidney injury by downregulating the oxidative stress- related pathway in ischemia-reperfusion rats. Cell Transplant 2016; 25(3): 517- 530.

34. Gheisari Y, Ahmadbeigi N, Naderi M, Nassiri SN, Nadri S, Soleimani M. Stem cell-conditioned medium does not protect against kidney failure. Cell Biol Int 2011; 35(3): 209- 213.

35. Xing L, Cui R, Peng L, Ma J, Chen X, Xie R, Li B. Mesenchymal stem cells, not conditioned medium, contribute to kidney repair after ischemiareperfusion injury. Stem Cell Res Ther 2014; 5(101):136.12- Dorronsoro A, Robbins PD. Regenerating the injured kidney with human umbilical cord mesenchymal stem cell-derived exosomes. Stem Cell Res Ther 2013; 4(39): 1- 3.

36. Dorronsoro A, Robbins PD. Regenerating the injured kidney with human umbilical cord mesenchymal stem cell-derived exosomes. Stem Cell Res Ther 2013; 4(39):1- 3

37. Zou X, Zhang G, Cheng Z, Yin D, Du T, Ju G, Miao S, Liu G, Lu M, Zhu Y. Microvesicles derived from human Wharton's jelly mesenchymal stromal cells ameliorate renal ischemia-reperfusion injury in rats by suppressing CX3CL1. Stem Cell Res Ther 2014; 5 (40): 1- 13.

38. Bruno S, Grange C, Collino F, Deregibus MC, Cantaluppi V, Biancone L, Tetta, C, Camussi G. Microvesicles derived from mesenchymal stem cells enhance survival in a lethal model of acute kidney injury. PLoS ONE 2012; 7(3): 11 pages.

39. Monsel A, Zhu YG, Gudapati V, Lee JW. Treatment of Lung Disease by Mesenchymal Stromal Cell Extracellular Vesicles. In: Atkinson K. (Ed), The Biology and Therapeutic Application of Mesenchymal Cells, Volume I and II, 1st edition, ch. 38, John Wiley and Sons, Inc., Hoboken, New Jersey, USA 2017; 553- 572.

40. Zou X, Gu D, Xing X, Cheng Z, Gong D, Zhang G, Zhu Y. Human mesenchymal stromal cell-derived extracellular vesicles alleviate renal ischemic reperfusion injury and enhance angiogenesis in rats. Am J Transl Res 2016; 8(10): 4289- 4299.

41. Camussi G, Deregibus MC, Cantaluppi V. Role of stem cell derived microvesicles in the paracrine action of stem cells. Biochem Soc Trans 2013; 41: 283 - 287. 
الملخص العربى

\section{دراسة نسيجية ونسيجو كيميائية مناعية لدور الخلايا الجذعية والوسط المحيط والحويصلات الدقيقة

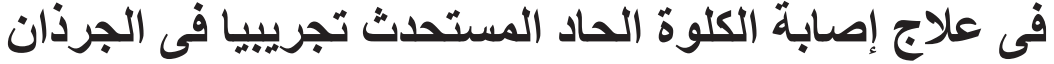 \\ ميسرة محمود سالم1، أميمة كامل هلال1، هالة جبر متولى أحمد، أسماء محمد الهادى1،}

\section{1قسم الأنسجة وبيولوجيا الخلية ـ كلية الطب جامعة بنها - بنها ـ مصر 2قسم الباثولوجيا الإكلينيكية ـ كلية الطب ـ جامعة القاهرة ـ القاهرة ـ مصر}

المقدمة: إن الإصابة الحادة للكلوة هى مشكلة صحية كبيرة مرتبطة بمعدلات عالية من التدهور و الوفاة. و الخلايا الميز انشمية

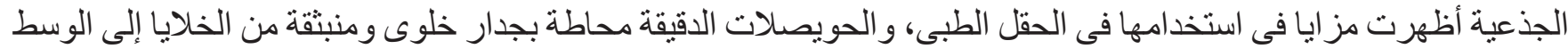
الدقيق المحيط بها. و الوسط المحيط هو الوسط الخئ الخارجى حول الخلايا الجذعية.

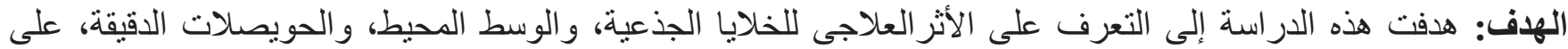

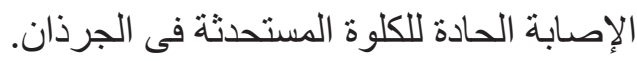

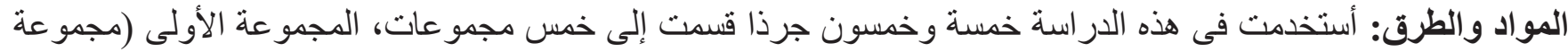

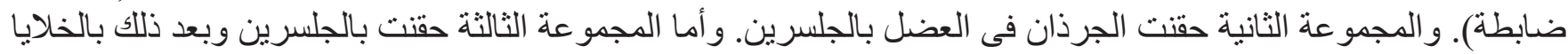

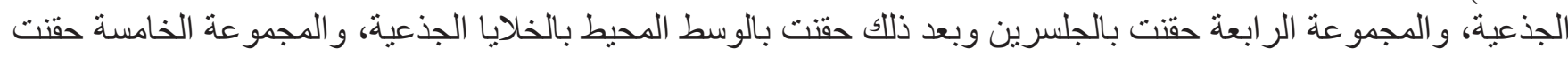
بالجلسرين وبعد ذلك حقتت بالحويصلات الدقيقة. وجهزت بلإلت عينات من الكلى لصبغها الهيماتوكسلين والإيوسين، وكى أى-67، وللفحص بالمجهر الإلكترونى.

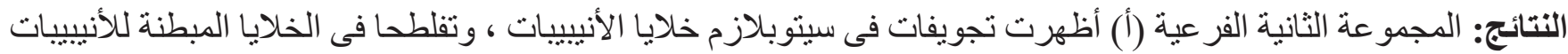

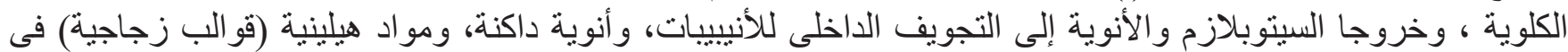

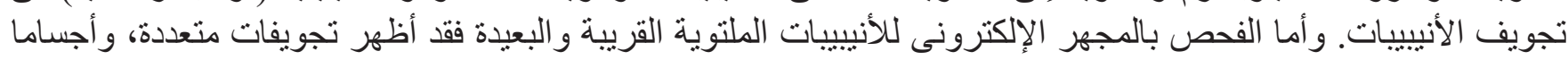

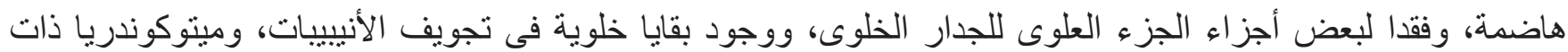
تجاويف، وأظهرت المجموعة الفرعية (ب) تحسنا ضئيلا لهذه التغيرات. و على الجانب الآخر أظهرت المجموعات التهات الثالثة

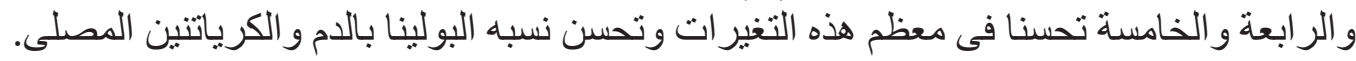

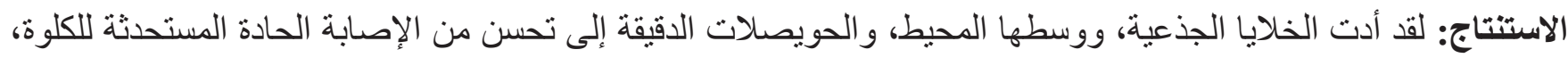
مع تغير ات طفيفة فيما بينها فى نسبة تأثثر ها. ولذلك يمكن استخدام الوسط المحيط و الحويصلات الدقيقة فى علاج الأمر اض. لاض. 